\title{
The typological learning framework: the application of structured precedent design knowledge in the architectural design studio
}

\author{
Robert Grover $^{1}$ (D) $\cdot$ Stephen Emmitt $^{1} \cdot$ Alexander Copping $^{1}$
}

Accepted: 20 July 2017/Published online: 16 August 2017

(C) The Author(s) 2017. This article is an open access publication

\begin{abstract}
In the architectural design process, built precedent can be a valuable resource to shape design situations. Typology, the systematic categorisation of precedent, may act as a means to interpret this information and identify relationships between existing buildings and new design. This work explores the link between typology and the design process and asks how typological thinking may benefit novice designers in the context of the architectural design studio. The research conceptually synthesises theories of typology with design methods to provide a practical framework for the application of typology in design studio teaching. Adopting a stage-based model of design, underpinned by the critical method as a description of individual design cycles, the framework offers a means of guiding project decisions, encouraging ideation and accessing information embedded in design precedents. The research is exploratory in nature and adopts a participant observation approach to develop and test the proposed framework. This is supported by data gathered from case studies, structured interviews and questionnaires. The typological learning framework is supported by the results of the research and considers various interpretations of typology at each stage in the design process, analytical processes required and practical guidance for designers and educators.
\end{abstract}

Keywords Architecture · Critical method · Design studio · Precedent · Typology

\section{Introduction}

When dealing with the complexity of architectural design, precedent can be a valuable tool for encouraging ideation and analysing concepts. Despite widespread use in the architectural design studio, knowledge extraction from examples is often limited in scope and depth, especially among novice designers. Moreover, the variety of precedents chosen is

Robert Grover

r.j.grover@bath.ac.uk

1 Department of Architecture and Civil Engineering, University of Bath, Bath BA2 7AY, UK 
often restricted to buildings with direct functional similarities or easily replicable visual tropes. This paper proposes a structured framework for extracting knowledge embedded in precedent and tests it in the context of a first year architectural design studio.

While numerous studies of precedent integration exist, much of the literature assumes an overtly mechanised processes of design. Studies into case based design (CBD), drawn from research in computer sciences and artificial intelligence (AI), suggest that adapting and combining previous architectural examples produces positive solutions without hindering creativity (Schmitt 1993). Automated systems such as those described by Maher and Gómez de Silva Garza (1997) adopt procedural interpretations of the design process and an assumed mechanised formulation of architectural creation.

A number of computational systems have been developed to aid the identification and extraction of relevant precedent information including EDAT (Akin 2002), ArchIMap (Tunçer 2009), DYNAMO (Heylighen et al. 2007), ProductWorld (Muller and Pasman 1996) and PRECEDENTS (Oxman and Oxman 1993). These tools either lack an organizational structure or use pre-defined categorisation which require significant input from either the user or the creator to populate with information. There is little work done on how knowledge extraction varies through the design process or how it may falsify or corroborate proposed solutions and be used to inform decision making in inexperienced architects.

Studies looking at the extraction of design knowledge from analogical thinking (Wu and Weng 2012) or metaphors (Casakin 2004, 2006, 2011; Casakin and Miller 2007). Casakin (2006) have concluded metaphorical thinking was particularly valuable early in the design process. Eilouti (2009) drew similar conclusions, suggesting precedent information could inform a pre-design phase, presenting frameworks for the extraction of knowledge from example projects.

This work synthesises research in design methods with historical theories of typology to provide a framework that guides knowledge extraction from precedent at throughout the design process. The framework maybe used to guide decision making and corroborate or reject trial proposals.

\section{Background}

\section{Design methods}

The nature of architectural design is complex, time-consuming and often contradictory. Architects are asked to deal with competing factors from multiple stakeholders in order to synthesise a satisfactory solution. The various theories of design methodologies that arose in the 1960s considered it a reductive science adopting a positivist approach stance (Newell et al. 1958; Marples 1961; Thornley 1962; Archer 1964; Krick 1965) exemplified by Simon (1969). In Simon's view, even the most complex of design situations could be broken down into their constituent parts and tackled with traditional problem solving techniques. In this paradigm, design could be understood as a process of analysis of the problem followed by synthesis of the solution.

Throughout the 1970s, alternatives to procedural methodologies arose embracing heuristic activity either as hermeneutic process (Hillier et al. 1972; Darke 1979) or a reflective one (Schön 1985). The critical method (CM) (Brawne 2003; Wright 2011) falls within this canon and is explicitly advocated at the case study University. CM has its 
foundations in the work of Popper (1963) and understands design as a cyclical process of initial conjecture followed by an analysis of the proposed solutions and then the elimination of errors, which then go on to form subsequent conjecture. This was first articulated by Darke (1979) who also proposed an initial phase termed the primary generator which pre-structures design situations through the experiences, prejudices and personal interests of the architect.

A key tenet of Popper's critical rationalism is that in order for scientific conjecture to be valid, it must be falsifiable and seeking definitive proof is impossible. The strength of a theory relies on its ability to withstand attempts to invalidate it. Conversely, in the description of CM provided by Brawne (2003), he claims that architecture cannot be falsified while Wright (2011) presents a variety of conjectural types yet does not suggest criteria for rejection. One is left asking how decisions are made in the design studio and what constitutes a false solution or, in the terminology of Brawne, how does one undergo error elimination?

As the design processes and the design situation takes on ever increasing definition, the nature and types of decisions the architect makes change. Various authors have described staged based models of design (Asimow 1962; Watts 1966; French 1985; Hubka and Eder 1988; Pahl et al. 2007) which invariably frame the process of one of gaining gradual definition from abstract conceptualisation to concrete product. The Royal Institute of British Architect's Plan of Work (Royal Institute of British Architects 2013) describes an eight stage process, the first five of which deal with design (from strategic definition to technical design) and is commonly used in the UK construction industry.

Wright (2011) aligns CM with a roundel model of the design process suggested by Smithies (1981) whereby through an iterative process, the designer gradually spirals in towards an ideal solution. Nevertheless, it is unclear how individual heuristic cycles operate within this structure.

\section{A typological framework}

Typology, understood as the study of categorising precedents, may provide an effective tool to structure the extraction of information embedded in precedent. Historical discourse has generally considered three distinct interpretations: typologies of architectural origins (exemplified in Enlightenment thinking of Quatremère de Quincy); typologies of construction and physical production (exemplified by early twentieth century modernism); and typologies of urban morphology and social production (promoted by neo-rationalist thinking) (Vidler 1977; Moneo 1978; Güney 2007).

Argan (1963) provides an alternative structure aligning typologies with a notional 3 stage model of the design process consisting of organisation, structure and decoration. This typological system shares considerable similarities with the theory for studying past architectural works by Anay (2007) which recognises any architectural work as consisting of a number of constructive elements: intent, design concept, form, programme and structure (construction, materials and technique). Table 1 draws from the work of Anay and Argan and re-structures the historical discourse creating a hierarchical model of typology defined by types of embedded design information.

The hierarchy described provides a framework for interpretation of a single precedent. Metaphors, systems and elements may be extracted from any instance to enable effective design knowledge recycling. 
Table 1 Hierarchy of typologies

\begin{tabular}{lll}
\hline Typology & Types of information & Examples of exponents \\
\hline Metaphorical & Cultural & Quatremère de Quincy (1832) \\
& Contextual & Vidler (1977) \\
& Experiential & Rossi et al. (1982) \\
& Historical & Carl (2011) \\
& & Kärholm (2013) \\
Systemic & Spatial & Krier et al. (1988) \\
& Structural & Von Meiss (2013) \\
Elemental & Organisational & \\
& Parts & Vitruvius (Rowland and Howe 2001) \\
& Conditions & Alberti (1775) \\
& Moments & Durand (1809) \\
& Functional & Alexander et al. (1977) \\
\hline
\end{tabular}

\section{A typological learning framework}

This research combines a hierarchical typological structure with a stage based model of the design process and tests the assumption that typologies operate in a sequential manner at different stages in the design process. Moreover, the proposed framework, attempts to integrate the heuristic cycles of CM into this overarching model, providing suggested design activities at each stage.

The theoretical framework shown in Fig. 1 proposes an expanding project space as the project gains definition. It is suggested that metaphorical typologies operate early in the design process and may be aligned with the initial definition of the project frame (the cultural, symbolic and experiential context of the project), systemic typologies with the concept design phase (organisational strategies) and elemental typologies at the detail design phase (emulation and adaption of parts and conditions embedded in precedent). The hierarchy of typologies is such that increasing number of types are employed as the design progresses with metaphors providing the greatest overall structure but with the fewest number of examples while elements provide the least amount of project definition yet multiple types are employed. As the overall project space expands it also gains definition however the designer may loop back at any point to an earlier stage.

At each design phase, a four stage heuristic process is defined consisting of an initial conjecture, then a process of analysis which involves the identification and formation of typologies, their association and application to the initial conjecture, and a verification stage. The designer may then circulate back to attempt another conjecture in a cyclical process.

\section{Research method}

\section{The context of the research}

The architecture curriculum at the case study university has developed over the past 50 years, based on the work of a number of former prominent educators notably Smithies (1981) and Brawne (2003). The critical method (CM) underpins the current ethos of the 


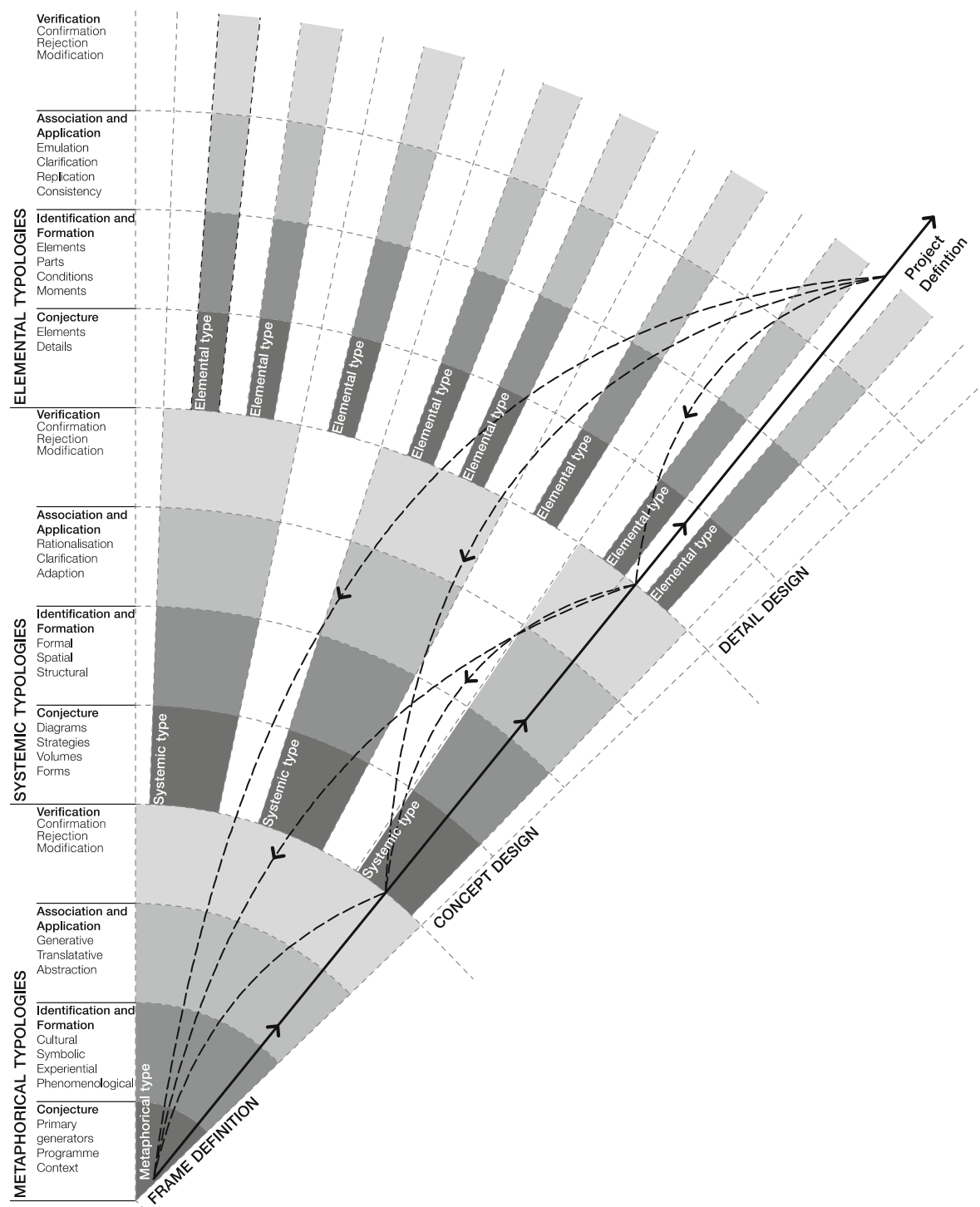

Fig. 1 The typological learning framework (first published by the author 2016, MPhil Thesis)

undergraduate degree and is described by Wright (2011). According to Wright, the explicit use of $\mathrm{CM}$ as a pedagogic model was first introduced to the case study department's undergraduate and postgraduate design studio models in 2005. At this time, both permanent staff and visiting tutors were exposed to the method and expected to implement it in their teaching practice.

Since the introduction of CM, it has been directly taught to undergraduate students of architecture who are made aware of its role in the design studio. Exposing students to a design model can have 'a profound and beneficial effect' (Wilkinson 2016) by suggesting a 
framework which may be used to structure architectural thought (Curry 2014). Collaborative design forms a corner stone of the educational model employed. Initially, architects are jointly educated with Civil Engineers and undergo a number of combined projects throughout their undergraduate education. Each year contains approximately 100 architecture and 100 civil engineering students from which groups are formed. This collaboration encourages an understanding of design which is both practical and legible, requiring the need for communication of design ideas to those beyond the architectural community.

The design studio at the case study university shares many similarities with that described by Schön (1985) and has indeed changed little throughout modern architectural education. The research uses this environment as an abstraction and simplification of the architectural design process to explore the notion of typology.

\section{Method}

The case study university was selected as the researcher was employed there as an educator. This allowed access to data, resources and participants as well as familiarity with the educational context.

A sample of eight students, randomly assigned to the researcher as a tutor group, acted as participants in the study, avoiding observer selection bias. The research used a participant observation approach and the researcher was able to develop relationships with the students, mimicking the intended application of the framework. It also ensured the participants were not getting additional teaching or help beyond normal studio hours avoiding potential ethical issues.

The participants were all from a single architecture school, of a similar age with similar educational backgrounds (evidenced by the admission requirements at the case study university) and identical levels of architectural education. Moreover, the limited resources available and the specific and idiosyncratic nature of the observation meant a smaller group size was considered. A group of eight students participated in the research, representing the tutor group of the researcher. The author had a joint role of both researcher and educator allowing strong interpersonal relationships to be developed, essential to the nature of the research, and meant prolonged engagement and persistent observation could be undertaken (Cohen et al. 2000).

Conventional reliability and validity may be achieved through the reduction of bias (Cohen et al. 2000) however the naturalistic nature of the research meant complete impartiality was unavoidable. The researcher's preconceptions, expectations and misinterpretation of findings all represent possible sources of bias. Combined with the possibility of participant misunderstanding, behaviour modification in the presence of the researcher and unrepresentative sampling, conventional understanding of validity was undermined. (Cohen et al. 2000, p. 129). Accepting the inevitability of bias, the results of the research were considered to be trustworthy (Lincoln and Guba 1985). To be 'trustworthy' the study was considered to be credible, confirmable, transferable and dependable (Cohen et al. 2000).

Lincoln and Guba (1985) outline various techniques of how researchers may meet the criteria for credibility. Prolonged engagement in the context of the naturalistic study is required to learn the culture and test for misinformation, which was achieved through the observer's experience as a former student of architecture, and tutor. Persistent observation describes the need for the researcher to act with salience and openness to identify elements 
of any situation that may contribute to the issue being examined. Further credibility was given by the data triangulation from multiple sources (interviews, observations of workshops, written feedback, project work). Member checks (verification of findings with the participants) provided confirmability as did ongoing data analysis which was continuously checked against findings. Transferability was achieved through recording and describing the context of the research. Changes in the context and nature of the data collection sessions are described in the methodology and results and provide a level of dependability.

The research was conducted through four workshops in consecutive weeks of a first year undergraduate design project. The participants were asked to design a brick house for a photographer of their choice on an abstract site, $12 \mathrm{~m} \times 18 \mathrm{~m}$. Each house was detached and sat in a notional landscaped park.

The workshops were designed to map the design process and examine a different notions of typology within the defined framework. As the workshops progressed, the role of the instructor also changed depending on the nature of the typologies. These roles were drawn from the six category intervention defined by Heron (1976) and modified by Yürekli (2013). In the initial workshops the teacher acted as a supporter and catalyst to encourage personal typology formation by the participants and independent project frame definition. In the later stages of the project, when the frame had taken definition, the teacher's role switched to one of informant and prescriber matching the finite elemental nature of the typologies. These roles are set out in Table 2 .

\section{Workshop 1}

\section{Frame definition: metaphorical typologies}

The first workshop sought to convert initial primary generators into independently defined conceptual types. Initially participants were asked to form and abstract the problem frame, in this case based around the theme of photography. They were then asked, as an independent exercise, to identify ways in which buildings may be categorised. As a group these categories were ordered into typologies and types, facilitated by the instructor. The participants were then asked to consider what types of building may relate most closely to their initial abstract concepts. The session took approximately $3 \mathrm{~h}$ : the first was used to

Table 2 Workshop structure

\begin{tabular}{lllll}
\hline $\begin{array}{l}\text { Workshop } \\
\text { (week) }\end{array}$ & Design stage & Typology & Intended outcomes & Role of teacher \\
\hline 1 (week 1) & $\begin{array}{c}\text { Frame } \\
\text { definition }\end{array}$ & Metaphors & $\begin{array}{l}\text { Translation of written brief } \\
\text { Translation of abstract primary } \\
\text { generators } \\
\text { Definition of architectural model } \\
2 \text { (week 2) }\end{array}$ Concept \\
design & Systems & $\begin{array}{l}\text { Definition of system types } \\
\text { Research and identification of } \\
\text { appropriate types }\end{array}$ & Catalytic \\
4 (week 4) & Detail design & Elements & $\begin{array}{l}\text { Establish opening and compositional } \\
\text { types }\end{array}$ & Inform \\
& Detail design & Elements & $\begin{array}{c}\text { Establish opening and compositional } \\
\text { types }\end{array}$ & Inform/prescribe \\
\hline
\end{tabular}


define their photographic theme in a 'mood board', the second to define metaphorical types and organise these into typological categories, and the third to associate their metaphorical definitions with the defined types and find precedents (within sample material provided) which participants felt matched these typologies. The intended outcome of the workshop was for each student to construct an independent typological frame to act as a primary generator. The identification with typologies also acted as an aid to select relevant precedents for consideration with future design work.

\section{Workshop 2}

\section{Concept design: systemic typologies}

The second workshop took $90 \mathrm{~min}$ and considered the extraction and adaption of spatial typologies. The independent formation of types was developed and students were asked to consider a selection of unfiltered precedents and produce a spatial diagram of each (20 $\mathrm{min}$ ). The group then organised the spatial diagrams into types facilitated by the researcher $(20 \mathrm{~min})$. The exercise was then repeated with their own initial ideas, each of which was identified with a particular type $(20 \mathrm{~min})$. There was $15 \mathrm{~min}$ at the start to enable reflection on the previous week's workshop and $15 \mathrm{~min}$ at the end for feedback on this workshop. The intended outcome was to identify spatial types from a selection of precedents and identify initial ideas with these spatial types amongst novice designers.

\section{Workshop 3}

\section{Detail design: elemental typologies}

The third workshop took 40 min. Participants were presented with a number of building opening types and façade composition types by the researcher $(15 \mathrm{~min})$ and then asked to identify their projects with these types in turn, addressing the rest of the group (15 min). There was $10 \mathrm{~min}$ at the end to allow for feedback. This method was considered in relation to the independent typological formation of the earlier exercises. The intended outcome of the workshop was for students to associate their projects with opening and façade types to develop a clear strategy.

\section{Workshop 4}

\section{Detail design: elemental typologies}

The fourth workshop followed a similar format to the previous workshop. Again a didactic delivery method was used and the researcher presented different types of brick expression and ornamentation $(15 \mathrm{~min})$. This was followed by discussion around each of individual project $(15 \mathrm{~min})$. The intended outcome was for novice designers to consider the typological categorisation of brick ornamentation to provide coherent and consistent strategies for progression. There was $10 \mathrm{~min}$ at the end for feedback and reflection. 


\section{Data collection}

Data was collected via qualitative feedback forms at the end of each session, standardised interviews conducted at the end of the project, observations of the workshops and analysis of the completed design projects.

\section{Qualitative feedback questionnaires}

At the end of each workshop participants were asked to complete a qualitative feedback form to gauge the effectiveness of the session from a learner perspective. Each form asked four questions designed to elicit responses of different depths based on the analysis of learner feedback by Hoon et al. (2015). The participants were asked if the session had helped them to select relevant precedents, what the purpose of the session was, what was successful about the session and what could be improved. The first two questions were designed to establish whether each the session was suitably aligned to its intended outcomes through descriptive responses. The second questions focussed on successful aspects and potential change which have been shown to encourage deeper qualified and constructive responses (Hoon et al. 2015).

\section{Field notes}

At each workshop the researcher was an 'observer-as-participant' (Cohen et al. 2000), that is their role was made clear however the researcher did not fully engage with the activities of the group. Ongoing field notes were made and categorised in situ (Lincoln and Guba 1985). These were supplemented by reflective journals which allowed continuous postanalysis of observations.

\section{Standardised interviews}

At the end of the course standardised, open-ended interviews (Patton 1980) were conducted with the each participant individually. The interviews consisted of four open ended questions designed to elicit qualitative responses that gauged the efficacy of the particular workshops, the structure, order and format of the sessions and the perceived outcomes of the workshops. The interview format allowed the researcher to probe particular responses and facilitate deeper responses than was achieved in the feedback questionnaires. The structured nature of the interview allowed notes to be taken during the interview which avoiding the potentially threatening environments generated by using recording equipment (Cohen et al. 2000). It also allowed the interview to confirm written response with participants to avoid misinterpretation.

\section{Case study}

A case study was conducted in an ex post facto manner (Cohen et al. 2000) through analysis of a single student's design project. The project report acted as the data source which was then analysed and coded for instances of precedent adoption and typological constructions. This evidence was cross-referenced with the data collected in the specific workshops as well as the interview and feedback data relating to that student. 


\section{Data analysis}

The process of analysis and interpretation was drawn from Groat and Wang (2002) modified from Miles and Huberman (1994) and took the form of reduction, display and verification. Codes were added to the raw data based on the methodology outlined by Miles and Huberman (1994). Chunks of data was coded which was then clustered and subsequently recoded to aid effective grouping. Categories and sub-categories of data emerged that were used to draw results and inform conclusions.

Checklist matrices (Miles and Huberman 1994) were produced for each objective of the study and considered from an observer perspective and a participant perspective. These checklists were an amalgamation of the four data collection methods, of structured participant feedback, structured interviews, participant observation and visual evidence (in the form of workshop output and design product).

Following the creation of a matrix the analysis draws from the rules of thumb of conclusion drawing of Miles and Huberman (1994). Common themes and patterns were identified which were then verified through clustering of similarly coded items and comparing and contrasting. This informed written analysis that was then confirmed through triangulating with the data and informant feedback. The analysis process was simultaneous with data collection as it informed and directed further research, especially the direction of structured interviews. Through adopting a rigorous and consistent coding language, emergent from the data sent, researcher bias was mitigated.

\section{Results}

\section{Hierarchical typologies and process}

An analogous relationship between a stage-based model of the design process and a hierarchical understanding of typologies could be corroborated. The non-linear nature of design meant that although students were at different stages in the projects, each could draw relevance from the sessions and all students were able to participate in a meaningful way. The structure was supported by views of the students. In interviews, participants found value in the changing notion of typology. One student highlighted the different modes of application he employed throughout the design process:

All the way through I had some strong conceptual, abstract ideas which I used such as 2001: A Space Odyssey. Later in the design process I referred to specific buildings for details and picked and chose elements rather than looking at broad categories of types.

The participants generally considered the overall structure and strategy of the framework to be successful. As one student put it in interview 'the range of sessions was right for each stage of the design.' Participants expressed a desire for information to be frontloaded in the design process and as a result considered some sessions to fall too late. Nevertheless, most participants were able to adequately adapt, modify and interrogate their proposals with respect to new information suggesting it had some effect in overcoming design fixation. 


\section{Pedagogy}

Participants often considered the relationship between the tutor and student to be one of imparting knowledge rather than discovering and later sessions were considered more popular amongst students. Observations showed that early group sessions favoured more vocal, stronger students. Quieter students had to be prompted and the role of the tutor as a supporter was critically important to allow this however there was much stronger student engagement by all students. It was observed that group work, although encouraged interaction, left some group members alienated and not participating fully in the task. Some participants struggled with the active nature of the first workshop and some found it irrelevant, supported by comments made in the final interviews.

The first workshop was the least helpful as it was not in depth enough and they are things that I would consider on my own.

Others, however, appreciated the changing pedagogic delivery of the workshops:

Earlier on the more involved and interactive workshops were helpful however the presentations later on were good for dealing with specific problems.

In instructional sessions, participants were less able to form their own typologies when asked and reverted to the presented types or formed hybrid typologies that related to their projects. Presentations were preferred over finding own examples, partly due to the quality of material offered and the clarity of focus but also the feeling that the students were being 'taught'.

The presentation [was most useful] as it actually taught me something and helped me analyse my design.

The presentations were most useful as they introduced us to knowledge rather than having to find it ourselves which can be hard when we don't know what we are looking for.

However, participants when interviewed at the end of the project, found the content and the skills learnt in the systemic typologies workshop (diagramming of schemes) most valuable.

It was useful to know how to draw diagrams of buildings as it makes you think and put into practice. You need to have a diagram in mind when you design and this is something that is useful but not taught.

\section{Practical issues}

The observations revealed a number of practical issues that must be considered when implementing the typological framework. For the tutor, it was observed that a significant amount of time outside of the allotted tutorial time was required to prepare each session including research or relevant precedents and the production and distribution of materials. Inherent subjectivities of precedent choice and guidance formation could have limited the scope of the designs. Where the facilitator was required to provide significant guidance and act in a supporting role, experience, familiarity with content and skills were required.

From a participant standpoint, access to and quality of precedents information produced was of primary importance in all sessions. This was noted in both sessions involve printed 
material and presented material. Participants preferred high quality images and a vast range of material from drawings to imagery.

\section{Critiquing the framework}

Within each of the three stages of the design model, a number of operational processes were observed taking different forms at each stage. It was observed that typology generally operated at the analytical phase of $\mathrm{CM}$ and that following the conjectural phase, the heuristic process could be broken down into:

- Identification of typologies and formation of types.

- Association with proposal and application of type.

These processes are discussed in the context of the observed results at each stage of the process below.

\section{Frame definition stage}

In the frame definition phase of the project, it was observed that extracting architecturally relevant characteristics and identifying metaphorical typologies was challenging for most participants. Few participants were able to make connection between abstract ideas and typical situations or scenarios. Moreover, the formation of types was challenging to participants. Rather than creating metaphorical categories based on cultural, contextual or experiential phenomenon, when presented with and array of precedents, participants generally ordered them through physical characteristics. Figure 2 shows the typological categories formed by participants.

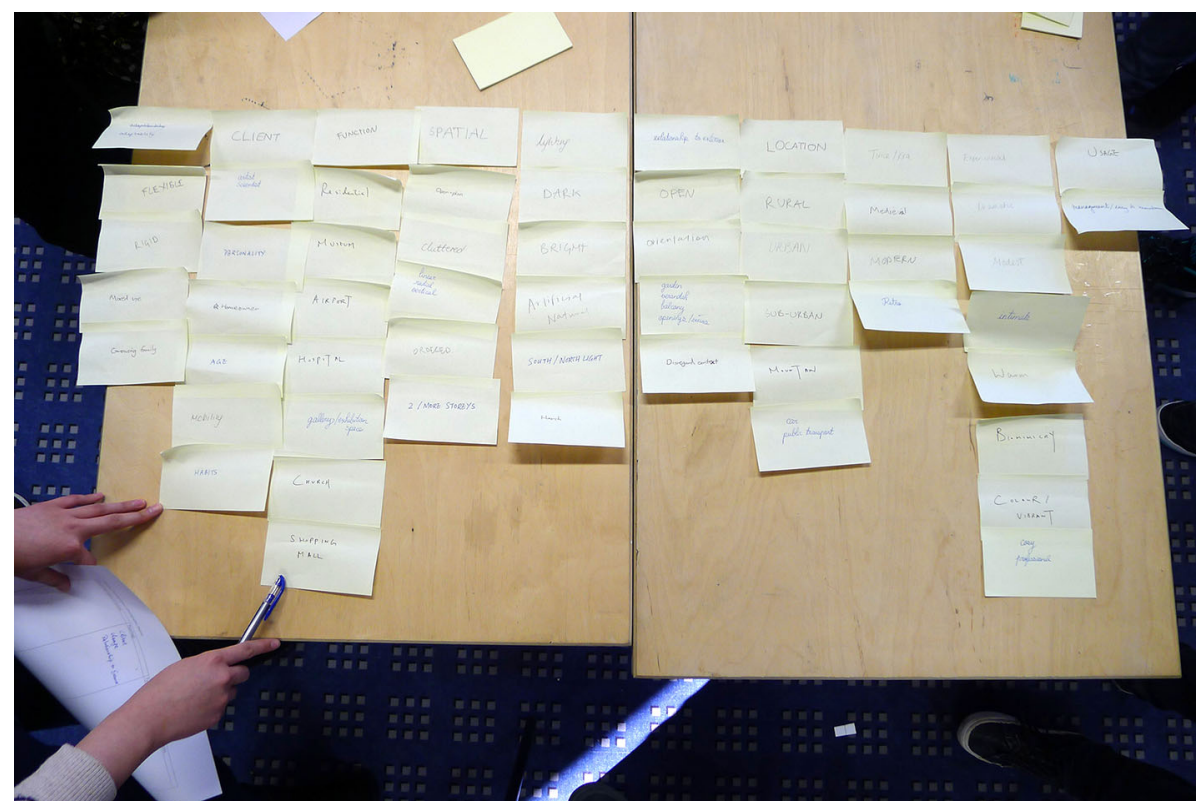

Fig. 2 Workshop 1 participant defined typological map 
In general, few students formed typologies but reverted to individual examples of precedent to extract metaphorical design information.

Figure 3 shows an example of a participant's work who developed the picture house as a typological category and identified formal aspects of the type. She was able to associate this to her initial brief but this was limited to easily identifiable characteristics of art-deco picture houses (the curved shapes and the signage). The work did not fully assess the cultural and historical factors that define the nature of the metaphor but showed a reduction of precedent to type and the beginning of a translation to the house.

Figure 4 shows early attempts to translate the metaphorical type however the bullet pointed text accompanying the images suggests a further elemental approach, breaking down the model type into easily replicable characteristics.

Interpretation of written brief acted as a barrier to adopting typologies. Participants were concerned over having the correct brief and complexity lead to tendency to fall back on deterministic methods to interpret and structure the project frame and were unable to associate with formed typologies. As an exception, one participant used the typology of a cinema to generate their building concept whilst another used the film 2001: A Space Odyssey and applied a translation to apply it to his design.

From a student perspective, feedback questionnaires from the initial workshop suggested there was little understanding on how typologies might inform future work despite it being the clear focus of the session. Most considered the initial design stages about understanding, clarifying and defining the brief through practical and client considerations rather than identifying typologies.

[I] learnt how to pinpoint the values of my building which will be important to the design and how they correspond to the user.

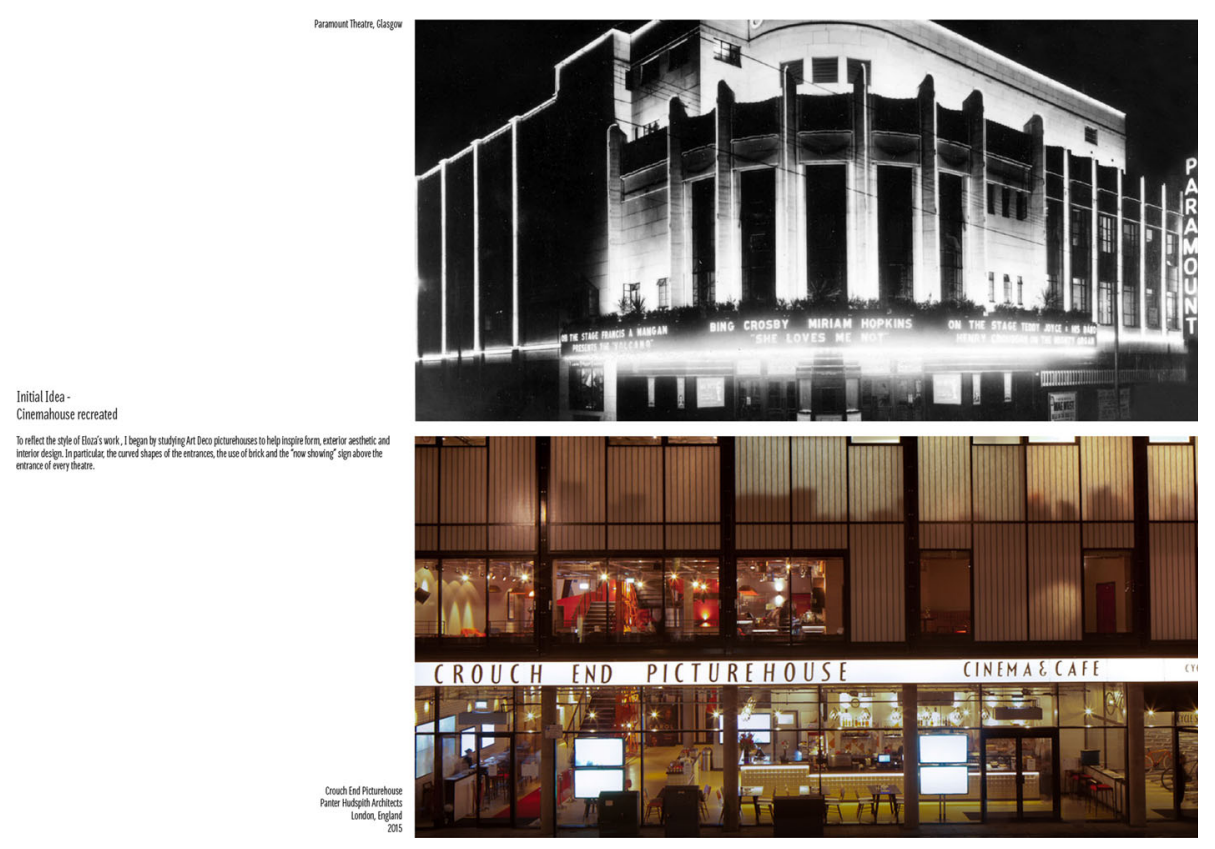

Fig. 3 Case study metaphorical typologies 

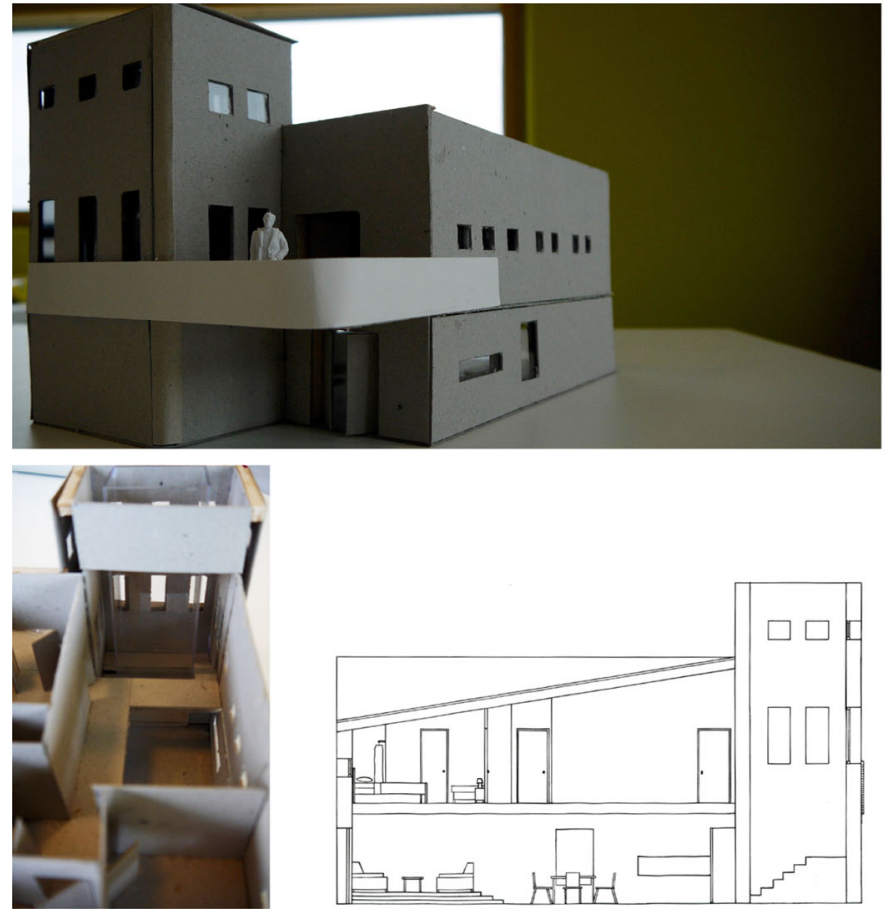

Initial Idea-
Cinemahouse recreated

Features:
slack brick,

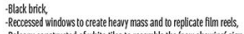

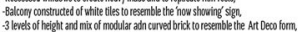

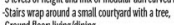

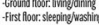

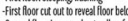

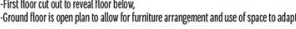

Fig. 4 Case study metaphorical typologies association and application

Most students however recognised the importance of framing the project in a consistent manner. When asked in feedback questionnaires after the first workshop what the purpose of the session was, one student responded that:

the purpose of the workshop was to analyse the task thoroughly and thereafter to lay

a strong base of the further design.

The first workshop was considered to be more helpful retrospectively by the participants suggesting they were more engaged with it once they had already begun to design with many students citing the value of typologies and precedent in the retrospective feedback one week after the workshop.

As we had decided on the precedents and the typology it was helpful for us to start designing the house.

\section{Concept design stage}

In most cases, participants were able to produce simple diagrams of both precedents and their own schemes and they were able to form types (Fig. 5). Examples of analysis, presented by the tutor, provided a clear insight into the process and students generally responded by creating similar drawings. The formation of types was led by the facilitator and it was observed participants found it challenging to reduce their scheme to sufficient levels to see shared characteristics with other precedents, although the diagramming process aided this (Fig. 6). 


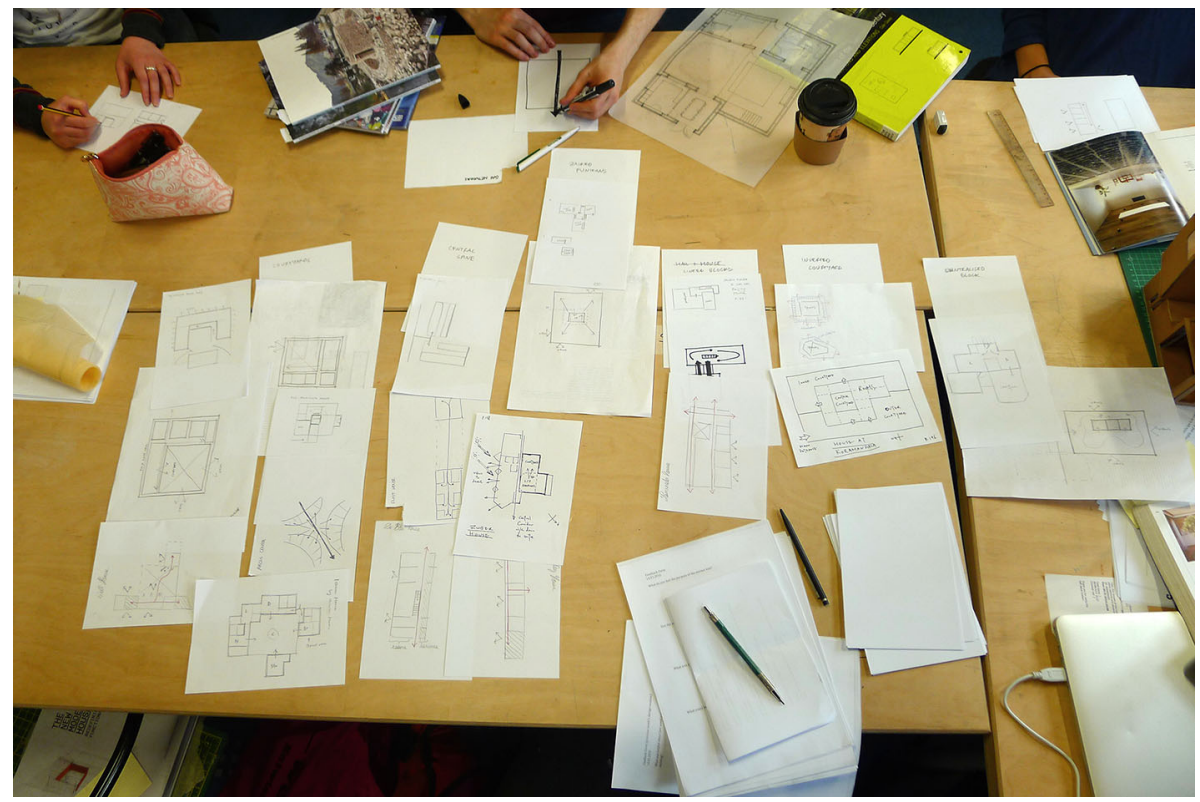

Fig. 5 Workshop 2 plan diagramming exercise

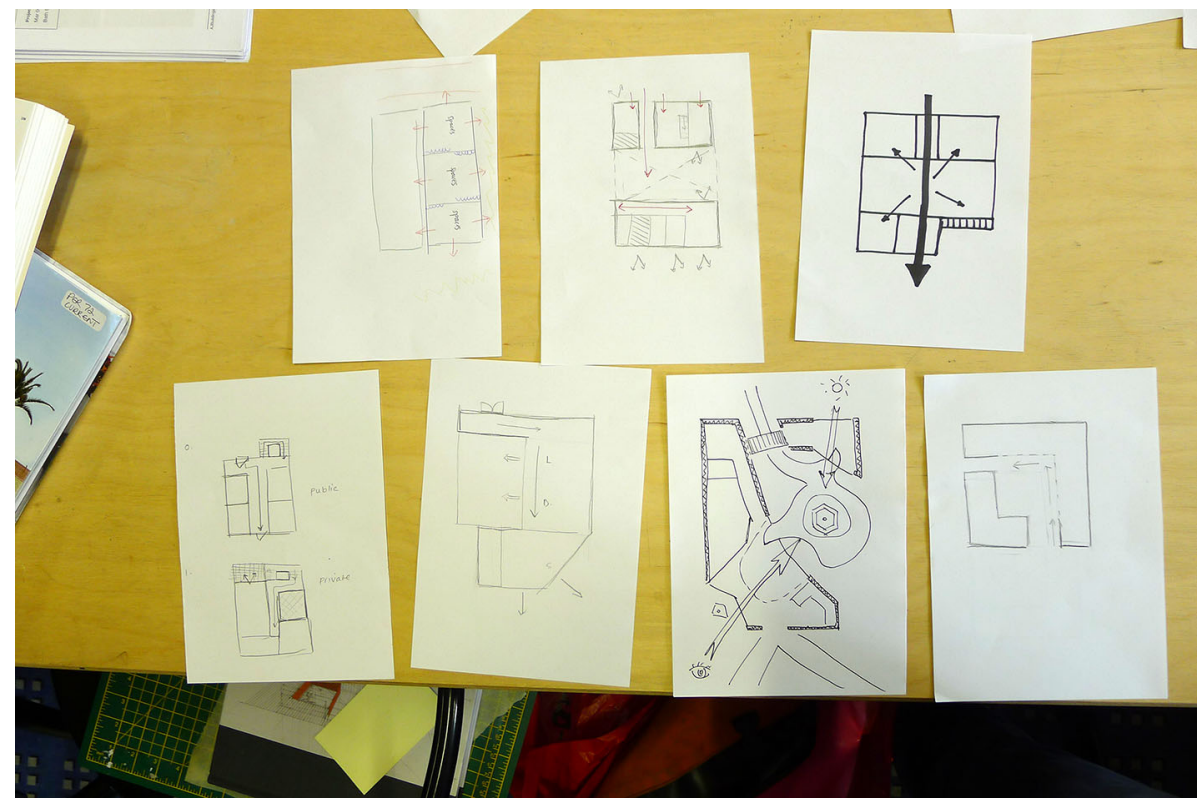

Fig. 6 Workshop 2 student scheme diagrams 
Feedback questionnaires from the second workshop showed participants found creating diagrams of precedents could reduce them to more understandable units.

It allowed us to think about plans in a simple way.

For many participants, the diagramming and arrangement of precedents into diagrams was considered practice for their own scheme rather than a means to relate to precedent. Nevertheless, the process of drawing diagrams prompted an abstraction of thought that allowed a detachment from the complexity of individual proposals and allowed participants to develop clarity in their ideas.

I understand how to simplify a plan to its core principles to help understand why the design works.

According to the feedback questionnaires from the second workshop, a further effect was that it guided participants to select relevant precedents.

I selected relevant precedents and understood their basic functions.

Despite the apparent success of the workshop and its popularity with participants, in completed design reports very few participants exhibited successful application of types despite strong identification and formation phases. Notwithstanding shortcomings in the association through typology, participants were observed to use the process to clarify and rationalize their proposals.

\section{Detail design stage}

At this stage instructional pedagogic techniques were utilised as in most cases a finite number of types could be predefined by the instructor. In a group of participants with a wider variety of projects such an instructional approach may not have been appropriate. An elemental approach meant all participants could identify with these and instantly spotted relationships to their schemes. It was observed that all students identified common outcomes of the workshops and found clarity in opening, façade and detail strategies. This was supported in the feedback questionnaire from the third workshop.

The purpose of the session was to consider different types of openings in our designs.

In general, elemental typologies were more easily understood and incorporated than more abstract concepts. Elemental types were generally used to corroborate and clarify existing designs or for emulation and replication. Few students created individual typologies but focused on presented types to add clarity to their proposals. Participants valued clarity in presentation as well as the quality and quantity of precedents, highlighted in the feedback from the 4th workshop.

Clear images and good choice of buildings to get the point across.

In the final interviews, one participant noted how exposure to elemental examples provided purpose and structure when seeking applicable examples for knowledge extraction.

The presentations [were most successful of the workshops] as they gave clear inspiration which was hard to find on my own when hunting for precedents. 
The presentation of elemental types was understood as an analytical tool by participants and feedback from the final interviews suggested it was generally used to provide a means of comparing individual proposals to types.

It's helped me to understand what works with my design and maybe what needs to be analysed further. Now I actually understand my design and where to go next.

In Fig. 7 the participant was able to identify typologies including the expression of the brickwork and the windows and apply them to her own scheme. The work presented suggests a focus on precedent rather than type, but the participant was able to categorise specific examples into more general axioms. She was then able to associate and apply these to her scheme in a coherent and logical manner (Fig. 8).

\section{Conclusion}

This research proposed a structured framework for the extraction of design knowledge information at different stages of the design process. It was conducted with novice designers, first year architecture students at the case study university, through a design studio project of a brick house. The participants had been exposed to CM as the dominant pedagogic paradigm employed in the studio (Wright 2011) and it is through this lens that the research is framed.

The research suggests that typological integration is most often occurs at the analysis phase of CM. Attempts to modify primary generators and translate them to typological project frames were generally observed to be unsuccessful. Following initial conjectures, typological analysis offered a valuable means of interpreting proposals.
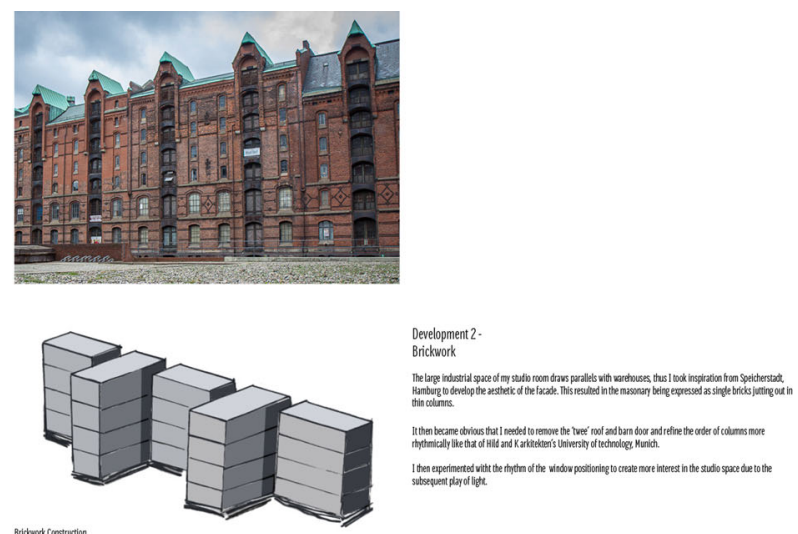

hidowouk Consturticn

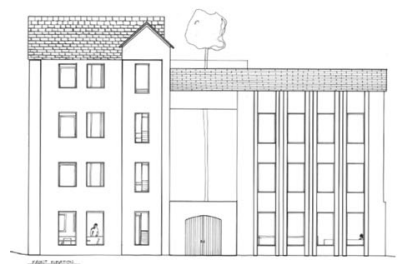

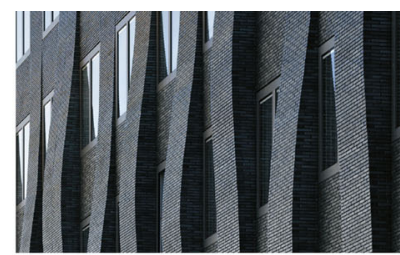

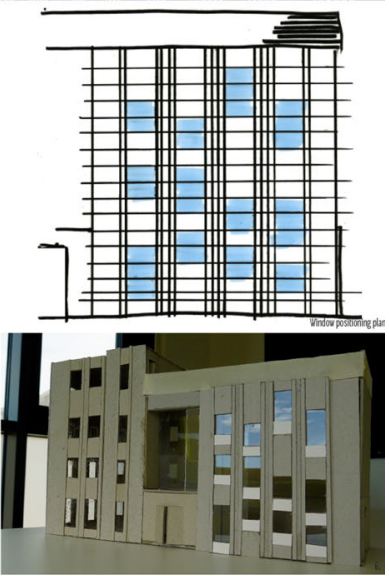

Fig. 7 Case study elemental typologies identification and formation 


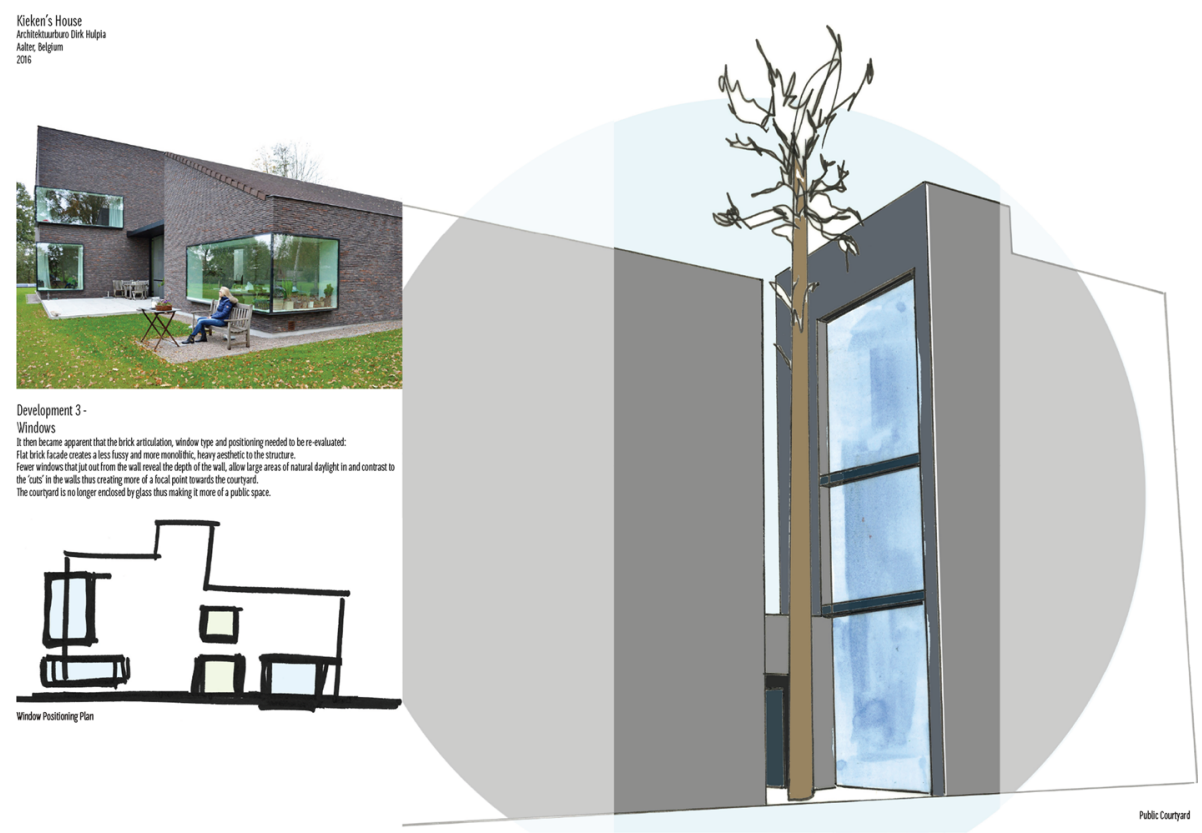

Fig. 8 Case study elemental typologies association and application

It appears valuable to attempt to encourage typological formation and the association with type throughout the design process. It allowed the extraction of a variety of embedded design information. It was observed that independent learner generation of typologies, for example the creation of spatial plan types, encouraged understanding and higher level of analytical thought.

The typological framework suggests a hierarchy of typologies can be mapped to the design process. In the project definition stage, metaphorical typologies requiring greater analysis and abstraction to reveal typical conditions were used to help shape project frames. At concept and early design stages, systemic typologies involving formal and spatial analysis provided general organisational strategies. At the detail design stage, typologies were understood in an elemental manner, used to solve specific design problems requiring low-level skills of analysis and adaption.

Participants often interpreted precedent at a basic level choosing precedents that followed function and emulating easily replicable physical attributes. They exhibited a tendency to extract specific knowledge from isolated instances rather than using a wide range of examples to formulate typologies and extract more general axioms. This may act as a barrier to design knowledge extraction, both in the limited pool from which precedents are drawn and the depth of analysis undertaken. This suggests a typological approach which avoids specific examples and focuses on typical conditions is a more effective means of extracting design knowledge for new proposals.

The findings appear to stand at odds with the conclusions of Casakin (2006) and Eilouti (2009) who found knowledge extracted from precedents to be most successful in early or pre-design phases. This discrepancy may be due to alternative formulations of the design process which assume a significant analytical phase preceding synthesis rather than the conjecture to analysis model advocated by $\mathrm{CM}$. The research suggests that through 
structured extraction of embedded knowledge, precedent analysis may be made effective at all design stages.

Educators in architecture and other related design disciplines may adopt the pedagogic methodology outlined. Although the supportive role of the tutor is a valued one, there is also a clear desire for more structured and traditional learning that takes place in parallel and with relevance to studio design projects.

It is recommended that the consideration of a wide range of types and typological formation should be encouraged. Isolating particular **buildings or designers may be unhelpful when attempting to extract more general design knowledge and a typological understanding of precedent helps to engender a wider range of design information extraction.

Open Access This article is distributed under the terms of the Creative Commons Attribution 4.0 International License (http://creativecommons.org/licenses/by/4.0/), which permits unrestricted use, distribution, and reproduction in any medium, provided you give appropriate credit to the original author(s) and the source, provide a link to the Creative Commons license, and indicate if changes were made.

\section{References}

Akin, Ö. (2002). Case-based instruction strategies in architecture. Design Studies, 23(4), 407-431.

Alberti, L. B. (1775). The architecture of Leon Battista Alberti in ten books. London: Leon Battista Alberti. Alexander, C., Ishikawa, S., \& Silverstein, M. (1977). A pattern language: Towns, buildings, construction (Vol. 2). Oxford: Oxford University Press.

Anay, H. (2007). Outline of a theory studying past architectural works. Paper presented at the International Association of Design Research, Hong Kong Polytechnic University.

Archer, L. B. (1964). Systematic method for designers. Council of Industrial Design.

Argan, G. C. (1963). On the typology of architecture. Architectural Design, 33, 564-565.

Asimow, M. (1962). Introduction to design (Vol. 394). Englewood Cliffs, NJ: Prentice-Hall.

Brawne, M. (2003). Architectural thought: The design process and the expectant eye. Oxford: Architectural Press.

Carl, P. (2011). Type, field, culture, praxis. Architectural Design, 81(1), 38-45.

Casakin, H. (2004). Metaphors in the design studio: Implications for education. Paper presented at the International Engineering and Product Design Education Conference, Delft, The Netherlands.

Casakin, H. (2006). Assessing the use of metaphors in the design process. Environment and Planning B: Planning and Design, 33, 253-268.

Casakin, H. (2011). Metaphorical reasoning and design expertise. Journal of Learning Design, 4(2), 29-38.

Casakin, H., \& Miller, K. (2007). An investigation of metaphor use and learning style in design problem solving. Paper presented at the International conference on engineering and product design education, Northumbria University, Newcastle-upon-Tyne, UK.

Cohen, L., Manion, L., \& Morrison, K. (2000). Research methods in education (5th Ed.). Teaching in Higher Education, 41. London: Routledge Falmer.

Curry, T. (2014). A theoretical basis for recommending the use of design methodologies as teaching strategies in the design studio. Design Studies, 35(6), 632-646. doi:10.1016/j.destud.2014.04.003.

Darke, J. (1979). The primary generator and the design process. Design Studies, 1(1), 36-44.

Durand, J. N. L. (1809). Précis des leçons d'architecture données à l'École polytechnique (Vol. 1). Paris: chez l'auteur, à l'Ecole polytechnique.

Eilouti, B. H. (2009). Design knowledge recycling using precedent-based analysis and synthesis models. Design Studies, 30(4), 340-368. doi:10.1016/j.destud.2009.03.001.

French, M. J. (1985). Conceptual design for engineers. London: Springer.

Groat, L., \& Wang, D. (2002). Architectural research methods. New York: Wiley.

Güney, Y. I. (2007). Type and typology in architectural discourse. BAÜ FBE Dergisi, 9(1), 3-18.

Heron, J. (1976). A six-category intervention analysis. British Journal of Guidance and Counselling, 4(2), $143-155$.

Heylighen, A., Neuckermans, H., Casaer, M., \& Dewulf, G. P. M. (2007). Building memories. Building Research and Information, 35(1), 90-100. 
Hillier, B., Musgrove, J., \& O’Sullivan, P. (1972). Knowledge and design. In W. J. Mitchell (Ed.), Environmental design research and practice (Vol. 29, pp. 1-14, Vol. 3). University of California.

Hoon, A., Oliver, E., Szpakowska, K., \& Newton, P. (2015). Use of the 'Stop, Start, Continue' method is associated with the production of constructive qualitative feedback by students in higher education. Assessment \& Evaluation in Higher Education, 40(5), 755-767.

Hubka, V., \& Eder, W. E. (1988). Theory of technical systems: A total concept theory for engineering design (Vol. 1). Berlin: Springer.

Kärrholm, M. (2013). Building type production and everyday life: Rethinking building types through actornetwork theory and object-oriented philosophy. Environment and Planning D: Society and Space, 31(6), 1109-1124. doi:10.1068/d15312.

Krick, E. V. (1965). An introduction to engineering and engineering design. London: Wiley.

Krier, R., Schnerider, R., \& Vorreiter, G. (1988). Architectural composition (Vol. 10). New York: Rizzoli.

Lincoln, Y. S., \& Guba, E. G. (1985). Naturalistic inquiry (Vol. 75). London: Sage.

Maher, M. L., \& Gómez de Silva, A. S. (1997). Case-based reasoning in design. IEEE Intelligent Systems, 12(2), 34-41.

Marples, D. L. (1961). The decisions of engineering design. IRE Transactions on Engineering Management, 2, 55-71.

Miles, M. B., \& Huberman, A. M. (1994). Qualitative data analysis: An expanded sourcebook. London: Sage.

Moneo, R. (1978). On typology. Oppositions, 13, 22-45.

Muller, W., \& Pasman, G. (1996). Typology and the organization of design knowledge. Design Studies, 17 , 111-130.

Newell, A., Shaw, J. C., \& Simon, H. A. (1958). Elements of a theory of human problem solving. Psychological Review, 65(3), 151.

Oxman, R., \& Oxman, R. (1993). Remembrance of things past: Design precedents in libraries. Automation in Construction, 2, 21-29.

Pahl, G., Beitz, W., Feldhusen, J., \& Grote, K.-H. (2007). Engineering design: A systematic approach (Vol. 157). Berlin: Springer.

Patton, M. Q. (1980). Qualitative evaluation methods. Beverly Hills, CA: Sage.

Popper, K. (1963). Conjectures and refutations (Vol. 7). London: Routledge and Kegan Paul.

Quatremère de Quincy, A. (1832). Dictionnaire historique d'architecture. Paris: le Clere.

Rossi, A., Eisenman, P., Ghirardo, D., \& Ockman, J. (1982). The architecture of the city. Cambridge, MA: MIT Press.

Rowland, I. D., \& Howe, T. N. (2001). Vitruvius: 'Ten Books on Architecture'. Cambridge: Cambridge University Press.

Royal Institute of British Architects. (2013). Plan of work. https://www.ribaplanofwork.com/. Accessed May 23, 2016.

Schmitt, G. (1993). Case-based design and creativity. Automation in Construction, 2, 11-19.

Schön, D. A. (1985). The design studio. London: RIBA Publications Ltd.

Simon, H. A. (1969). The science of design: Creating the artificial. The sciences of the artificial (pp. 111-138). Cambridge, MA: MIT.

Smithies, K. W. (1981). Principles of design in architecture. Berkshire: Van Nostrand Reinhold Company Ltd.

Thornley, D. G. (1962). Design method in architectural education. Paper presented at the Papers presented at the Conference on Systematic and Intuitive Methods in Engineering, Industrial Design, Architecture and Communications, London.

Tunçer, E. B. (2009). The architectural information map. Delft: Technische Universiteit Delft.

Vidler, A. (1977). The third typology. Oppositions, 7, 288-294.

Von Meiss, P. (2013). Elements of architecture: From form to place. Oxford: Routledge.

Watts, R. D. (1966). The elements of design. In The design method (pp. 85-95). Berlin: Springer.

Wilkinson, M. (2016). Origin of joint course in Architecture and Civil Engineering at the University of Bath. Paper presented at the Integrated Design: Building our Future, Bath, 29/06/16-01/07/16.

Wright, A. (2011). Critical method: A pedagogy for design education. Design Principles and Practices, 5(6), 109-122.

Wu, Y.-W., \& Weng, K.-H. (2012). Using an analogical thinking model as an instructional tool to improve student cognitive ability in architecture design learning process. International Journal of Technology and Design Education, 23(4), 1017-1035. doi:10.1007/s10798-012-9219-3.

Yürekli, A. (2013). The six-category intervention analysis: A classroom observation reference. ELT Journal, 67(3), 302-312. 